\title{
Design and Evaluation of Topical Hydrogel Formulation of Aceclofenac for Improved Therapy
}

\author{
Vinita Singh*, Neelesh Chaubey \\ Sri Satya Sai University of Technology \& Medical Sciences, SH-18, Bhopal-Indore Road Sehore (M.P.)
}

\begin{abstract}
Aceclofenac, a non-steroidal anti-inflammatory drug has been used in the treatment of rheumatoid arthritis and osteoarthritis. In order to decrease the gastric ulcerogenic effects, aceclofenac hydrogel have been developed. Topical gel preparations are intended for skin application or to certain mucosal surfaces for local action or transdermal penetration of medicament or for their emollient or protective action. Topical delivery of drugs can be achieved by incorporating drug into the gel matrix for effective delivery of drugs, thus avoiding first pass metabolism and for increased local action in pain management and skin diseases. NSAID's are non-steroidal drugs having excellent anti-inflammatory and analgesic activity but NSAID's produces GIT ulceration, liver and kidney trouble especially in case of oral ad ministration. In view of adverse drug reaction associated with oral formulations, many NSAID's are increasingly administered by topical route. Hydrophilic polymers like Guar gum and Carbopol 940 of varying concentrations were used in an attempt to develop topical hydrogel formulations of aceclofenac. Evaluation tests for visual appearance, pH, viscosity, spreadability, assay, in vitro drug release were carried out. In vitro diffusion study was carried out in a Franz diffusion cell using cellophane membrane. No prominent changes in physicochemical properties of formulation were observed after exposure to accelerated conditions of temperature $\left(40 \pm 2{ }^{\circ} \mathrm{C}\right)$ and humidity conditions $(75 \pm 5 \% \mathrm{RH})$. The gel formulation consisting of $1 \% \mathrm{w} / \mathrm{v}$ Guar gum 1\% w/v Carbopol 940 at 1:1 ratio was found to be suitable for topical application based on in vitro evaluation. These results suggest the feasibility of the topical gel formulation of aceclofenac.
\end{abstract}

Keywords: Aceclofenac, Guar gum, Carbopol 940, Topical hydrogel, Franz diffusion cell

Article Info: Received 19 June 2019; Review Completed 10 Aug 2019; $\quad$ Accepted 22 Aug 2019; $\quad$ Available online 15 Sep 2019

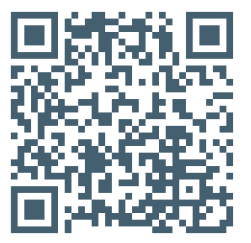

Cite this article as:

Singh V, Chaubey N, Design and Evaluation of Topical Hydrogel Formulation of Aceclofenac for Improved Therapy, Journal of Drug Delivery and Therapeutics. 2019; 9(5):118-122 http://dx.doi.org/10.22270/jddt.v9i5.3605

*Address for Correspondence:

Vinita Singh, Sri Satya Sai University of Technology \& Medical Sciences, SH-18, Bhopal-Indore Road, Sehore (M.P.)

\section{INTRODUCTION}

Osteoarthritis $(\mathrm{OA})$ is the most prevalent disease after the age of 65 in about $60 \%$ of men and $70 \%$ of women 1 . OA is primarily a non-inflammatory degenerative joint disease characterized by progressive loss of articular cartilage, subchondrial bone sclerosis, osteophyte formation, changes in the synovial membrane, and an increased volume of synovial fluid with reduced viscosity and hence, changed lubrication properties. Current treatment options for OA are limited. They include intra-articular (IA) injection of glucocorticoids and hyaluronic acid (HA) preparations or symptomatic treatment with simple non-steroidal antiinflammatory drugs (NSAIDs) ${ }^{2}$. Due to the localized nature of the disease, the IA injection of glucocorticoids and HA seems to be an attractive approach for OA, but they provide only short-term pain relief and/or often do not provide adequate pain relief and have no patient compliance 2 . On the other hand, Rheumatoid arthritis (RA) is a common chronic systemic inflammatory disease that is primarily characterized by inflammation of the synovium with destruction of cartilage and bone as the disease progresses. More severe disease may be associated with vasculitis, pericarditis, pleural effusion, pulmonary interstitial fibrosis, peripheral neuropathies, subcutaneous and pulmonary nodules and scleritis ${ }^{3,4}$. Since there is no cure, symptomatic treatment is the only choice to reduce the pain and inflammation. Formulations of NSAIDs are the first choice remedies which would fulfill the need of providing significantly long remission of pain with improved patient compliance. Aceclofenac (ACF) is a non-steroidal antiinflammatory drug (NSAID) and has been indicated orally for the relief of pain and inflammation in osteoarthritis, rheumatoid arthritis, and ankylosing spondylitis ${ }^{5,6}$. However, the oral administration of ACF has often resulted in side effects, including gastrointestinal ulcer and anemia due to gastrointestinal bleeding ${ }^{7}$. It requires frequent oral dosing because of its short half-life (3-4 h). Topical administration of ACF would be a possible alternative offering distinct advantages such as elimination of the absorption variable rate, first pass intestinal and hepatic metabolism inherent with oral dosing and delivering the 
drug directly to the inflamed site and thereby, producing high local concentrations and avoiding the side effects ${ }^{8}$. Topical administration of therapeutic agents offers many advantages over oral and intravenous administrations. Hydrogel based drug delivery system is a most promising novel approach now-a-days for delivery of drug for extended period of time. Hydrogels are the three-dimensional network polymers that swell in aqueous solutions and in swollen state, these become soft and rubbery, resembling a living tissue and some possess excellent biocompatibility. Hydrogel systems possesses a good stability in surrounding conditions like change in $\mathrm{pH}$, ionic strength, temperature and frequent changes of environment in the GI-tract, which has a variation of environment from the stomach to intestine 9. Hydrogel from natural polymers, especially polysaccharides have been widely used for their advantages over synthetic polymers such as non-toxic, biocompatible, biodegradable, freely available, able to modify the properties of aqueous environment, capable of thicking, emulsify, stabilize, encapsulate and swell and to form gels films. But they can be modified to overcome some drawbacks, like uncontrolled rate of hydration, microbial contamination, drop in viscosity on storing, etc ${ }^{10}$. In present work, attempt was made to formulate and evaluate topical hydrogel drug delivery systems. Attempts were made to enhance drug absorption and exposure to improve therapy by controlling the rate of drug release from dosage forms. Rate of drug release was modified using cross-linking agents, gelling or thickening agents. The ultimate aim was to improve bioavailability of the drug and to improve the market formulation by the use of combination of hydrophilic polymers.

\section{MATERIALS AND METHODS}

\section{Materials}

Aceclofenac was obtained as a gift sample from Yarrow Chemical Ltd, Bombay. Carbopol- 940 (Loba Chemie Pvt. Ltd., Mumbai, India), Guargum (Qualigens Fine Chemicals, Mumbai, India), Benzalkonium chloride (Prime laboratories, Hyderabad), Isopropyl myristate (Alpha Chemika, Maharashtra, India), sodium hydroxide (Prime laboratories, Hyderabad), potassium dihydrogen phosphate (Alpha Chemika, Maharashtra, India ) were procured and used in this investigation. All other chemicals used were of analytical grade and were used without any further chemical modification.

\section{Determination of $\lambda_{\max }$ of ACF}

Accurately weighed $10 \mathrm{mg}$ of drug was dissolved in $10 \mathrm{ml}$ of $7.4 \mathrm{pH}$ buffer solution in $10 \mathrm{ml}$ of volumetric flask. The resulted solution $1000 \mu \mathrm{g} / \mathrm{ml}$ and from this solution $1 \mathrm{ml}$ pipette out and transfer into $10 \mathrm{ml}$ volumetric flask and volume make up with $7.4 \mathrm{pH}$ buffer solution. Prepare suitable dilution to make it to a concentration range of 5$25 \mu \mathrm{g} / \mathrm{ml}$. The spectrum of this solution was run in 200-400 $\mathrm{nm}$ range in U.V. spectrophotometer. A graph of concentration Vs absorbance was plotted.

\section{Formulation of aceclofenac topical hydrogel}

Hydrophilic polymers like guar gum and carbopol 940 were selected and $0.1 \mathrm{~N} \mathrm{NaOH}$ solution used as cross linking agent ${ }^{11,12}$. Carbopol 940 is soluble in water while guar gum produces colloidal dispersion in water. $0.1-5 \% \mathrm{w} / \mathrm{v}$ concentrations of polymeric dispersions were made separately and were found to be having good mechanical properties when guar gum and carbopol 940 colloidal dispersions mixed in certain proportions.

The topical hydrogels using different proportions were prepared as follows:

1. Hydrogels were fabricated using different concentrations of polymeric dispersions.

2. Different concentrations of carbopol940 colloidal dispersions were prepared using distilled water.

3. Different concentrations of guar gum colloidal dispersions were prepared using distilled water.

4. After complete dispersion, both the polymer solutions were kept in dark for $24 \mathrm{~h}$ for complete swelling.

5 . Dispersions of polymers were made using magnetic stirrer (500rpm). After dispersing carbopol940 in distilled water, colloidal dispersion of guar gum was added to it under magnetic stirring. $1 \% \mathrm{v} / \mathrm{v}$ isopropyl myristate and $0.25 \%$ $\mathrm{w} / \mathrm{v}$ benzalkonium chloride were added. Aqueous drug solution was added to the polymeric dispersion after addition of sodium hydroxide solution. Finally, the remaining distilled water was added to obtain a homogeneous dispersion of gel under magnetic stirring. The composition of different formulation was given in Table 1 .

Table 1 Different formulas of aceclofenac hydrogel

\begin{tabular}{|c|c|c|c|c|c|}
\hline \multirow[t]{2}{*}{ Ingredients (Mg) } & \multicolumn{3}{|c|}{ Formulation Code } & & \\
\hline & F1 & F2 & F3 & F4 & F5 \\
\hline Aceclofenac & 100 & 100 & 100 & 100 & 100 \\
\hline Carbopol-940 & 0.375 & 0.5 & 0.25 & 0.375 & 0.5 \\
\hline Guar gum & 0.05 & 0.5 & 0.375 & 0.375 & 0.375 \\
\hline Isopropyl myristate (ml) & 1 & 1 & 1 & 1 & 1 \\
\hline Benzalkonium chloride & 0.25 & 0.25 & 0.25 & 0.25 & 0.25 \\
\hline Purified water (q.s) & $100 \mathrm{ml}$ & $100 \mathrm{ml}$ & $100 \mathrm{ml}$ & $100 \mathrm{ml}$ & $100 \mathrm{ml}$ \\
\hline
\end{tabular}




\section{Evaluation of hydrogel}

\section{Physical characteristic}

The prepared hydrogel formulations were inspected visually for their $\mathrm{pH}$, colour, homogeneity, consistency, grittiness, texture and phase separation

\section{Determination of $\mathrm{pH}$}

The $\mathrm{pH}$ of hydrogel formulations was determined by digital $\mathrm{pH}$ meter. One gram of gel was dissolved in $25 \mathrm{ml}$ of distilled water and the electrode was then dipped in to gel formulation for $30 \mathrm{~min}$ until constant reading obtained. And constant reading was noted. The measurement of $\mathrm{pH}$ of each formulation was done in triplicate and average values were calculated ${ }^{13}$.

\section{Washability}

Formulations were applied on the skin and then ease and extent of washing with water were checked manually.

\section{Extrudability study}

The hydrogel formulations were filled into collapsible metal tubes or aluminium collapsible tubes. The tubes were pressed to extrude the material and the extrudability of the formulation was checked ${ }^{14}$.

\section{Spreadability}

Two glass slides of standard dimensions $(6 \times 2)$ were selected. The hydrogel formulation whose spreadability had to be determined was placed over one of the slides. The second slide was placed over the slide in such a way that the formulation was sandwiched between them across a length of $6 \mathrm{cms}$ along the slide. 100 grams of weight was placed up on the upper slide so that the hydrogel formulation between the two slides was traced uniformly to form a thin layer. The weight was removed and the excess of the hydrogel formulation adhering to the slides was scrapped off. The lower slide was fixed on the board of the apparatus and one end of the upper slide was tied to a string to which 20 gram load could be applied with the help of a simple pulley. The time taken for the upper slide to travel the distance of $6 \mathrm{cms}$ and separate away from lower slide under the direction of the weight was noted. The experiment was repeated and the average of 6 such determinations was calculated for each hydrogel formulation 15,16 .

\begin{tabular}{|cc|}
\hline Spreadability $=$ & $\mathrm{m} .1$ \\
$\mathrm{t}$ & $\mathrm{t}$ \\
\hline
\end{tabular}

Where, $\mathrm{S}=$ Spreadability $(\mathrm{gcm} / \mathrm{sec}), \mathrm{m}=$ weight tied to the upper slide ( 20 grams),

$\mathrm{l}=$ length of glass slide $(6 \mathrm{cms}), \mathrm{t}=$ time taken is seconds.

\section{Viscosity}

The measurement of viscosity of the prepared hydrogel was done using Brookfield digital Viscometer. The viscosity was measured using spindle no. 6 at $10 \mathrm{rpm}$ and $25^{\circ} \mathrm{C}$. The sufficient quantity of gel was filled in appropriate wide mouth container. The hydrogel was filled in the wide mouth container in such way that it should sufficiently allow to dip the spindle of the viscometer. Samples of the hydrogel were allowed to settle over $30 \mathrm{~min}$ at the constant temperature $\left(25 \pm / 1^{0} \mathrm{C}\right)$ before the measurements ${ }^{17}$.

\section{Drug content}

Accurately weighed equivalent to $100 \mathrm{mg}$ of topical hydrogel was taken in beaker and added $20 \mathrm{ml}$ of phosphate buffer $\mathrm{pH}$
7.4. This solution was mixed thoroughly and filtered using Whatman filter paper no.1. Then $1.0 \mathrm{ml}$ of filtered solution was taken in $10 \mathrm{ml}$ capacity of volumetric flask and volume was made upto $10 \mathrm{ml}$ with phosphate buffer $\mathrm{pH}$ 7.4. This solution was analyzed using UV spectrophotometer at $\lambda_{\max }$ $275 \mathrm{~nm}$.

\section{In-vitro drug release studies using the prehydrated cellophane membrane}

The prepared hydrogel was evaluated for in vitro drug release. In vitro diffusion study was carried out in a Franz diffusion cell using cellophane membrane. The cellophane membrane was mounted on the Franz diffusion cell. Formulation was applied through donor compartment on the dialysis membrane. Reservoir compartment was filled with $25 \mathrm{ml}$ phosphate buffer of $\mathrm{pH} 7.4$ The study was carried out at $37 \pm 1^{\circ} \mathrm{C}$ and at a speed of $100 \mathrm{rpm}$ for $8 \mathrm{~h}$. Samples were withdrawn from reservoir compartment at $1 \mathrm{~h}$ interval and absorbance was measured spectrophotometrically at $275.0 \mathrm{~nm}$. Each time the reservoir compartment was replenished with the same quantity of $7.4 \mathrm{pH}$ phosphate buffer 18,19 .

\section{Accelerated stability studies}

Stability studies were carried out on optimized formulation according to International Conference on Harmonization (ICH) guidelines. The formulation packed in aluminium tube was subjected to accelerated stability testing for 3 months as per ICH norms at a temperature $(40 \pm 2 \mathrm{oC})$ and relative humidity $75 \pm 5 \%$. Samples were taken at regular time intervals of 1 month for over a period of 3months and analyzed for the change in $\mathrm{pH}$, spreadability, drug content and in-vitro drug release by procedure stated earlier. Any changes in evaluation parameters, if observed were noted. Tests were carried out in triplicate and mean value of the observed values was noted along with standard deviation.

\section{RESULTS AND DISCUSSIONS}

The absorption maxima of ACF were determined by running the spectrum of drug solution in double beam ultraviolet spectrophotometer using concentration range of $5-25 \mu \mathrm{g} / \mathrm{ml}$ ACF in 7.4phosphate buffers. ACF showed a linear relationship with correlation coefficient of 0.999 in the concentration range of $5-25 \mu \mathrm{g} / \mathrm{ml}$ in phosphate buffer $\mathrm{pH}$ 7.4 Figure1. Melting point of drug was found $148-149^{\circ} \mathrm{C}$ while it was $149-150^{\circ} \mathrm{C}$ reported in standard monograph. All the data of preformulation study were found similar as given in standard monograph which confirmed that the drug was authenticated and pure in form and it could be used for formulation development of ACF -loaded hydrogel.

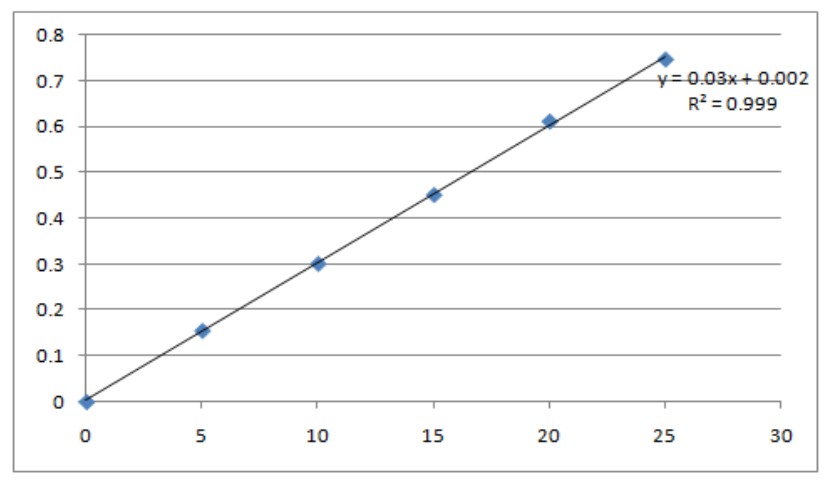

Fig.1 Calibration curve of ACF in phosphate buffer pH 7.4 at $275 \mathrm{~nm}$

Hydrogel formulations were white viscous creamy preparation with a smooth homogeneous texture and glossy 
appearance. Results have been discussed in Table 2. The results of washability, extrudability and spreadability of all formulation were given in Table 3 . From the result it was found that formulation F1-F5 has good washability ability, formulation F2, F3 has good Extrudability and Spreadability of all formulation was found to in range of 12.25to14.56. The viscosity of the hydrogel was obtained by using brookfield digital viscometer. The viscosity of the formulations increases as concentration of polymer increases and $\mathrm{pH}$ of prepared hydrogel were measured by using $\mathrm{pH}$ meter (Orion Research, Inc., USA). The pH of the hydrogel formulation was in the range of 6.95 to 7.05 which considered acceptable to avoid the risk of skin irritation upon application to skin and drug content of F2 was found to be higher 99.7 table 4 .

Table 2 Physical parameter of formulation batches

\begin{tabular}{|c|c|c|c|c|}
\hline Formulation & Colour & Homogeneity & Consistency & Phase separation \\
\hline F1 & White & Excellent & Excellent & None \\
\hline F2 & White & Excellent & Excellent & None \\
\hline F3 & White & Excellent & Excellent & None \\
\hline F4 & White & Excellent & Excellent & None \\
\hline F5 & White & Excellent & Excellent & None \\
\hline
\end{tabular}

Table 3 Result of washability extrudability and spreadability study

\begin{tabular}{|c|c|c|c|}
\hline Formulation & Washability & Extrudability & $\begin{array}{c}\text { Spreadability } \\
\text { (gcm/sec) }\end{array}$ \\
\hline F1 & +++ & ++ & 12.25 \\
\hline F2 & +++ & +++ & 13.36 \\
\hline F3 & +++ & +++ & 14.56 \\
\hline F4 & +++ & ++ & 13.23 \\
\hline F5 & +++ & ++ & 14.56 \\
\hline
\end{tabular}

Excellent: +++, Good: ++, Average: +, Poor: -

Table 4 viscosity, $\mathrm{pH}$ and drug content

\begin{tabular}{|c|c|c|c|}
\hline Formulation & Viscosity (cps) & pH & Drug Content \\
\hline F1 & $9344 \pm 2$ & 7.05 & $98.5 \pm 0.2$ \\
\hline F2 & $9589 \pm 2$ & 7.02 & $99.7 \pm 0.1$ \\
\hline F3 & $9436 \pm 1.5$ & 6.95 & $99.5 \pm 0.2$ \\
\hline F4 & $9242 \pm 2.5$ & 6.98 & $99.4 \pm 0.1$ \\
\hline F5 & $9180 \pm 1.5$ & 7.05 & $99.2 \pm 0.3$ \\
\hline
\end{tabular}

Release of drug from ACF hydrogel was significantly slower, which confirmed that slight prolonged drug release rate. Incorporation of carbomer affected the release rate of the drug. By increasing the amount of carbomer, the release rate of the drug decreased, which could be related to the increased rigidity of the formulation, followed by its decreased permeability for the drug. Optimized formulation F2 shows significantly improved in drug release rate as compare to marketed preparation. It was concluded that developed formulations deliver the drug for the treatment of OA Table 5.

Table $5 \%$ Cum. drug release of formulation F1-F5

\begin{tabular}{|c|c|c|c|c|c|c|c|}
\hline \multirow[t]{2}{*}{ Time (min) } & \multicolumn{7}{|c|}{ Cumulative $\%$ of drug release } \\
\hline & F1 & F2 & F3 & F4 & F5 & & Marketed \\
\hline 5 & $73.2 \pm 0.3$ & $29.3 \pm 0.4$ & $75.6 \pm 0.5$ & $52 \pm 1$ & 45. & \pm 0.7 & 42.23 \\
\hline 10 & $74.3 \pm 0.2$ & $38.0 \pm 0.3$ & $79.7 \pm 0.2$ & $58.4 \pm 0.4$ & 57.2 & \pm 0.05 & 65.56 \\
\hline 15 & $76.4 \pm 0.1$ & $39.6 \pm 0.3$ & $81.4 \pm 0.4$ & $71.3 \pm 0.2$ & $64.3^{3}$ & \pm 0.2 & 76.89 \\
\hline 20 & $77.9 \pm 0.1$ & $47.9 \pm 0.7$ & $81.6 \pm 0.2$ & $73.4 \pm 0.4$ & 68.6 & \pm 0.5 & - \\
\hline 30 & $80.8 \pm 0.3$ & $88.2 \pm 0.5$ & $82.6 \pm 0.6$ & $80.5 \pm 0.3$ & 75.1 & \pm 0.3 & - \\
\hline
\end{tabular}

changes were not noticed. The formulation F2 was found to be stable after exposure to accelerated temperature and humidity conditions for a period of 3 months. No significant changes were seen in physical evaluation parameters and given in the table 6. 
Table 6 Physical parameters after accelerated stability study of formulation F2

\begin{tabular}{|c|c|c|c|c|}
\hline \multirow{2}{*}{ Physical Parameter } & \multicolumn{2}{l|}{ Temperature: $40 \pm 2{ }^{\circ} \mathrm{C} ;$ Relative humidity (RH): $75 \pm \mathbf{5 \%}$ RH } \\
\hline & Initial & After 1 month & After 2 month & After 3 month \\
\hline pH & $7 \pm 0.06$ & $6.9 \pm 0.06$ & $6.9 \pm 0.06$ & $6.9 \pm 0.06$ \\
\hline Assay & $99.6 \pm 0.1$ & $99.5 \pm 0.1$ & $99.4 \pm 0.1$ & $99.3 \pm 0.1$ \\
\hline Viscosity & $9589 \pm 2$ & $9591 \pm 1.7$ & $9595 \pm 2$ & $9597 \pm 2.3$ \\
\hline
\end{tabular}

\section{CONCLUSION}

The Aceclofenac hydrogel for topical application was formulated using guar gum and Carbopol 940 and evaluation tests were performed. Proper selection of polymers and their proportions is a prerequisite for designing and developing a transdermal drug delivery system. The formulated gels showed good homogeneity, good stability and better drug release rates when compared to marketed formulation.

\section{REFERENCES}

1. Sarzi-Puttini P, Cimmino MA, Scarpa R, Caporali R, Parazzini F, Zaninelli A, Atzeni F, Canesi B. Osteoarthritis: an overview of the disease and its treatment strategies. Semin. Arthritis Rheum 2005; 35: 1-10.

2. Gerwin N, Hops C, Lucke A. Intra-articular drug delivery in osteoarthritis Adv Drug Deliv Rev 2006; 58: 226-242.

3. McKay N, Kelly CA. Extra-articular features of rheumatoid arthritis. Medicine 2006; 34: 383-386.

4. Zarrin Ghalam Moghaddam J, Naghade M. Comparison of the effect of Hirudo medicinals and Pyroxicam capsule on reduction of inflamation and pain in the primary stages of rheumatoid arthritis of knee. Iranian J Pharm. Res 2004; 3: 4343.

5. Chakraborty S, Khandai M, Sharma A, Khanam N, Patra CN, Dinda SC, Sen KK. Preparation, in vitro and in vivo evaluation of alginopectinate bioadhesive microspheres: an investigation of the effects of polymers using multiple comparison analysis. Acta Pharm 2010; 60:255.

6. Dua K, Pabreja K, Ramana MV. Aceclofenac topical dosage forms: in vitro and in vivo characterization. Acta Pharm2010; 60:467.

7. Lee J, Lee Y, Kim J, Yoon M, Choi YW. Formulation of microemulsion systems for transdermal delivery of aceclofenac. Arch Pharm Res 2005; 28: 1097-1102.
8. Shaikh IM, Jadhav KR, Gide PS, Kadam VJ, Pisal SS. Topical delivery of Aceclofenac from lecithin organogels: preformulation study. Cur Drug Deli 2006; 3: 417-427.

9. Chein YW. Novel drug delivery system. 2nd ed. Morcel Dekker. Inc, 1997; 1-42.

10. Panda N, Panda KC, Reddy AV, Reddy GVS. Process optimization, formulation and evaluation of hydrogel \{guargum-gpoly (acrylamide)\} based doxofylline microbeads. Asian J Pharm Clin Res 2014; 7(3): 60-65.

11. Wood PJ, Braaten JT, Scott FW, Riedel D, Poste LM. Comparisons of viscous properties of oat and guar gum and the effects of these and oat bran on glycemic index. J Agric Food Chem1990; 383: 753-757.

12. Avinash H, Hosmani,Thorat YS, Kasture PV. Carbopol and its pharmaceutical significance: A review. Pharm Reviews 2006.

13. Jain A, Gautam SP, Gupta Y, Khambete H, Jain S. Development and characterization of ketoconazole emulgel for topical drug delivery. Der Pharmacia Sinica 2010; 1(3): 221-231.

14. Gupta GD, Gaud RS. Release rate of Nimesulide from different gellants. Ind J Pharm Sci 1999; 61: 229-234.

15. Sanjay, Jain BD, Padsalg A, Patel K, Mokale V. Formulation development and evaluation of fluconazole gel in various polymer bases formulation development and evaluation of fluconazole gel in various polymer bases. Asn J Pharm 2007; 1: 63-68.

16. Gupta GD, Gaud RS. Release rate of Tenoxicam from Acrypol gel. The Indian Pharmacist 2005; 69-76.

17. Margaret N, Mutimer CR, Hill JA, Murray E. Modern ointment base technology comparative evaluation of bases. J American Pharm Association 1956; 4: 212-217.

18. Thomas AP, Dubey R, Jain P. Formulation and evaluation of ethosomal gel of tazarotene for topical delivery. Asian J Pharm2019; 13 (1):37-45.

19. Mishra R, Shende S, Jain PK, Jain V. Formulation and evaluation of gel containing ethosomes entrapped with tretinoin. J Drug Deli Therap 2018; 8(5-s): 315-321. 